\title{
SOLID WASTES OF FRUITS PEELS AS SOURCE OF LOW COST BROAD SPECTRUM NATURAL ANTIMICROBIAL COMPOUNDS- FURANONE, FURFURAL AND BENEZENETRIOL
}

\author{
Soma Roy ${ }^{1}$, Prashanth Lingampeta ${ }^{2}$ \\ ${ }^{1}$ Chaitanya Bharathi Institute of Technology, Biotechnology Department, Hyderabad, India \\ ${ }^{2}$ Chaitanya Bharathi Institute of Technology, Biotechnology Department, Hyderabad, India
}

\begin{abstract}
The present study investigates the antimicrobial potential of five fruits peel waste (pineapple, custard apple, jackfruit, pomegranate and papaya) extracted in four solvents (chloroform, petroleum ether, acetone, benzene) against clinical isolates of gram positive and gram positive pathogenic bacteria. The fruit peels chosen for the study were done so based on their high amount of waste (unused disposed portion) of peels and the common consumption of these fruits in India. GC-MS Analysis was carried out to find out the nature of the compounds responsible for the antimicrobial activity. The antibacterial potential was assessed by measuring the diameter of the zones of growth inhibition, MIC and MBC values. Amongst the solvents tested, acetone extract was seen to exhibit the best antimicrobial activity, thereby indicating it to be suitable for antimicrobial extraction. Maximum activity was seen for the acetone extracts, in the order of pomegranate peels > jackfruit peels > custard apple peels. GC-MS analysis of these acetone extracts showing encouraging antimicrobial activity revealed prominent peaks of furanone, furfural (along with imidazole) and phenolic compounds (mainly benezenetriol), there by indicating their role in the observed antimicrobial activity. This report is the first of its kind to analyze the reusability potential of acetone extracts of these fruit peel wastes for developing natural antimicrobials.
\end{abstract}

Keywords: Fruit peel wastes, antimicrobial activity, GC-MS, Furanone, Phenolic compounds $* * *$

\section{INTRODUCTION}

Research focusing on the potential application of natural antimicrobial compounds in food, cosmetic and pharmaceutical industries has gained considerable importance owing to the growing number of antibiotic resistant pathogens (Rao and Rao 2007). The emergence of antibiotic resistance has been linked to the overuse of antibiotics which helps the bacteria to adapt to the drugs through alteration in their genetic makeup (Paterson et al. 2004). In the recent years, apart from medicinal plants, fruits, which are a rich source of bioactive compounds, have become popular subjects for such investigations.

Considerable amount of solid wastes in the form of peels and seeds are generated by the fruit processing industries, and these wastes if not disposed correctly are seen to cause serious environmental problems such as water pollution, unpleasant odors, explosions and combustion, asphyxiation, and greenhouse gas emissions. There are several reports highlighting the integral exploitation of bioactive compounds from these wastes and their potential applications as antioxidant, antimicrobial, flavoring, colorant, and texturizer agents (Ashok Kumar et al. 2011; Ayala Zavelaet al. 2011). Solid wastes, particularly from processes such as peeling and coring, typically have a high nutritional value and may be used as animal feed. (VikashKandari and Sanjay Gupta 2012). Obtaining value added products from fruit wastes economizes the fruit processing units.
Jackfruit (Artocarpusheterophyllus lam), generates huge amount of solid wastes, as its seeds and peel. The peel waste of jackfruit has been reported for anaerobic biohydrogen production (VijayaraghavanKrishna et al. 2006), and the nano sized powder of the seeds have been studied for their antimicrobial potential (Theivasanthiet al.2011). Pineapple also has a major portion of it in the form of peel wastes, and the peels have been anaerobically digested to yield biogas in form of methane (SwaroopaRani.and Krishna Nand 2004). Research has been carried out to exploit the antimicrobial potential of methanolic, ethanolic and aqueous extracts of pomegranate peels (Al Zorekyet al. 2009; JahirAlam Khan and SonaliHanee 2011). Studies comparing theantioxidant properties of pomegranate peel with that of the pulp has revealed that the peel yields double the amount of antioxidants compared to the pulp(Li, Yunfenget al. 2006).The sugar components of custard apple peels were explored with a view to establishing their raw material potential and TLC results indicated the presence of lactose, sucrose, galactose and glucose(Chandrajuet al.2012).. Processing of custard apple peel sugars for biogas production has been reported by Narayani and GomathiPriya (2012). In the case of papaya, its seed waste has been tested and reported for its antimicrobial potential (Calzadaet al. 2007).

The present study was taken up to investigate the antimicrobial potential of the fruit peel wastes of pineapple, custard apple, jackfruit, pomegranate and papaya, extracted 
in four solvents (chloroform, petroleum ether, acetone, benzene),against clinical isolates of pathogenic bacteria. Phytochemical profiling through GC-MSof these fruit peel extracts were taken up so as to get insight into the compounds responsible for the antimicrobial activity and thereby pave way for indirect waste MANAGEMENT by transforming these wastes into a health resource.

\section{MATERIALS AND METHODS}

Unused waste peel portions of pineapple, custard apple, jackfruit, pomegranate and papaya were obtained from local fruit shops, washed thoroughly under tap water and shade dried at room temperature $\left(35-37^{0} \mathrm{C}\right)$ till completely dry. The dried peel pieces were powdered in an electric blender and the powder was stored in close containers until further usage.

\subsection{Solvent Extraction and Yield}

The solvents used for the present study included chloroform, petroleum ether, acetone and benzene. $10 \mathrm{gms}$ of each fruit peel powder was extracted with $200 \mathrm{ml}$ of each solvent. The extracts were filtered through Whattman filter paper No.1 and concentrated using rotavapor. The yield was calculated as grams of the extract obtained after drying. Each of the dried extract of the fruit peel was stored in closed vial at $4^{0} \mathrm{C}$. Working stocks were prepared by dissolving each fruit peel extract in appropriate amount of respective solvent so as to obtain a final concentration of $50 \mathrm{mg} \mathrm{ml}^{-1}$.

\subsection{Antimicrobial Activity}

Eight clinically isolated pathogenic bacterial strains that included five gram negative bacteria (Escherichia coli, Klebsiella pneumoniae, Pseudomonas aeruginosa, Proteus vulgaris, Salmonellatyphii)and three gram positive bacteria (Streptococcus pyrogenes, Staphylococcus aureus, Enterococcus faecalis) were used for the present investigation. The antimicrobial activity was tested using the agar well diffusion method (Okekeet al. 2001). For each bacterial test strain, $100 \mu \mathrm{l}$ of standardized bacterial stock suspension $\left(10^{8}-10^{9}\right.$ c.f.u ml-1)was thoroughly mixed with molten Mueller Hinton agar medium and poured into sterile petri plate. In each plate, three $8 \mathrm{~mm}$ wells were made using a sterile cork borer no. 4 . Next, $100 \mu \mathrm{l}$ of each of the fruit peel solvent stock solution extracts containing a concentration of $5 \mathrm{mg}$, were loaded into respective wells. As the positive control, $100 \mu \mathrm{l}$ of broad spectrum antibiotic, Amikacin containing $50 \mu \mathrm{g}$ was loaded. Loading the respective solvents with no extract served as the negative controls. The plates were incubated overnight at $37^{0} \mathrm{C}$. After incubation the diameters of the zones of inhibition were measured and tabulated for each fruit peel extract against each of the test microorganism. All the antimicrobial activity experiments were performed in triplicates.

\subsection{MIC and MBC}

Extracts with significant inhibition zones based on agar well diffusion method were evaluated for their MIC using two fold broth dilution method(Chattopadha yet al.1998). $1 \mathrm{ml}$ of each fruit peel extract was prepared at a concentration of 5 mgml-1 and was serially diluted two fold in sterile tubes containing $1 \mathrm{ml}$ of Mueller Hinton broth to achieve concentrations of $5,2.5,1.75,0.875$ and $0.437 \mathrm{mg} \mathrm{ml}^{-1}$. Bacterial inoculum $\left(0.1 \mathrm{ml}\right.$ of $10^{8} \mathrm{c}$.f.u ml $\left.\mathrm{m}^{-1}\right)$ were pipetted into the tubes and kept for incubation at $37^{\circ} \mathrm{C}$ for 24 hours. The lowest concentration tube that did not show any visible growth was considered as MIC. $0.1 \mathrm{ml}$ of each of the inoculated broths were transferred and spread onto fresh Mueller Hinton agar medium plates, and the tube containing the lowest concentration of the extract which did not show any visible growth on the plates was considered as MBC. All the assays were performed in triplicates.

\subsection{GC-MS Analysis}

For GC-MS analysis, the samples were injected into a DB 35 MS column, coupled with MSD detector. The temperature set was from $40^{\circ} \mathrm{C}-350^{\circ} \mathrm{C}$. The stepped up temperature program followed was as follows- held at $40^{\circ} \mathrm{C}$ for 2 minute, and then for every minute the temperature was increased by $10^{\circ} \mathrm{C}$ up to $350^{\circ} \mathrm{C}$. The injection volume was 1 $\mu 1$. The sample was injected in a split ratio of 1: 10 . Compound identification was obtained by comparing the retention times with those of authentic compounds and the spectral data obtained from library data of the corresponding compounds.

\section{RESULTS AND DISCUSSION}

\subsection{Antimicrobial Activity}

In the present investigation, fruit peel wastes of five fruits (pineapple, custard apple, jackfruit, pomegranate and papaya) were extracted in different solvents (chloroform, petroleum ether, acetone and benzene) and evaluated for their antimicrobial activity against clinical isolates of pathogenic bacteria (Escherichia coli, Klebsiella pneumoniae, Pseudomonas aeruginosa, Proteus vulgaris, Salmonella typhii, Streptococcus pyrogenes, Staphylococcus aureus, Enterococcus faecalis).

Table I depicts the overall comparative results for the antimicrobial activity potential exhibited by the different fruit peel extracts. It is seen that the acetone extract of pine apple peel showed moderate antimicrobial activity against all the tested bacteria with the highest zone of inhibition seen against Salmonella typhii $(18 \mathrm{~mm})$. In comparison, the other solvent extracts showed poor to nil activity.

Custard apple peel extract antimicrobial activity results show the acetone extract demonstrating fairly even and good antimicrobial activity, with the zones of inhibition ranging between $15-20 \mathrm{~mm}$ against all the tested pathogenic bacteria. Though chloroform extract and benzene extract of pine apple peel also showed antimicrobial activity, it was not much significant compared to the acetone extract results obtained.

Very good antimicrobial activity against all the tested pathogenic bacteria was observed with the acetone extract of jackfruit peels. Highest antimicrobial activity was seen in 
the acetone extract and the zones of inhibition ranged between 20-30 mm, with largest inhibition diameters seen against Klebsiella pneumoniae $(30 \mathrm{~mm})$ and Enterococcus faecalis $(30 \mathrm{~mm})$. The zones of inhibition are comparable to the inhibition zones observed using the standard antibiotic amikacin. The chloroform extract also is seen to exhibit fairly good antimicrobialactivity against Klebsiella pneumoniae, Proteus vulgaris and Enterococcus faecalis. (17 mm).

Very large diameters of zones of inhibition ranging between $30-35 \mathrm{~mm}$ were observed with the acetone extracts of pomegranate peels, thereby suggesting extremely high antimicrobial activity. Highest zones of inhibition $(35 \mathrm{~mm})$ were observed against Staphylococcus aureus and Enterococcus faecalis. Antimicrobial activity in pomegranate peels has been reported earlier, where theme thanolic extracts of pomegranate peels exhibited antimicrobial activity against food borne pathogens and phyto chemical analysis has revealed the presence of active inhibitors in peels including phenolics and flavonoids (Al Zorekyet al. 2009).Antimicrobial activity of ethanolic, methanolic and aqueous extracts of pomegranate peels have also been reported against E.coli, $P$. aeruginosa and $S$. aureus(Jahir, Alam, Khan and Sonali, Hanee 2011).

Papaya peel extracts exhibited the least antimicrobial activity amongst all the tested fruit peels in this study. In contrast to the other fruit peels, the antimicrobial activity observed was seen to be only in the chloroform extracts of papaya peels.

From the encouragingly large zones of bacterial growth inhibition observed, this study report clearly indicates the antimicrobial potential of the acetone extracts of the fruit peel wastes in the order of pomegranate peel>jack fruit $>$ custard apple. Similar results, depicting acetone being a suitable solvent for extraction of antimicrobial compounds from citrus fruit peels were reported by Ashok Kumar et al (2011).

The present investigation is the first of its kind to report the promising antimicrobial potential of acetone extracts of jackfruit peels, custard apple peels, pomegranate peels, and focuses on the possibility of using these peel wastes, that constitute a huge portion of the discarded part of these fruits, as sources of novel, low cost natural antimicrobials. The antimicrobial activity observed is seen to be equally effective against both, gram negative as well as gram positive pathogenic bacteria, there by demonstrating the broad spectrum nature of the antimicrobial compounds responsible for the activity and hence could be potential source for chemical classes of antibiotic substances that could serve as selective agents for infectious disease, chemotherapy and control.The results indicate that although most of the fruit peel solvent extracts demonstrated antimicrobial activity against the tested pathogenic bacteria, acetone as a solvent proved to be the ideal choice of solvent for extraction of antimicrobial compounds from the waste peels. Hence, choosing an appropriate solvent is very crucial for the selective extraction of fractions with high antimicrobial activity from natural sources.

\subsection{MIC and MBC}

The MIC is interpreted as the lowest concentration that inhibits visible microbial growth and expressed in terms of $\mathrm{mg} / \mathrm{ml}$, whereas the minimum bactericidal concentration (MBC) is interpreted as the lowest concentration that can completely remove the microorganism. The MIC and MBC were determined for the extracts showing very high potential antimicrobial activity, namely the acetone extracts of jackfruit peels, custard apple peels andpomegranate peels. As seen from Table II, the MIC values for all the three extracts ranged between 0.875 and $2.5 \mathrm{mg} / \mathrm{ml}$, while that of MBC ranged between 1.75 and $5.0 \mathrm{mg} / \mathrm{ml}$. Pomegranate peel extract showed the least MIC and MBC values when compared to the other two peel values, and this finding supports the present antimicrobial study which reports very high antimicrobial activity observed for pomegranate peel acetone extract. MIC values for jack fruit and custard apple peel acetone extracts were observed to be more or less similar against all the tested bacteria, except against Klebsiella pneumoniae and Pseudomonas aeruginosa, where the values were slightly higher for the custard apple peel extract. The MIC and MBC values of pomegranate peel extract against these two bacteria was observed to be higher too, thus indicating the high resistance of these bacteria.

\subsection{GC-MS Analysis}

The acetone extracts of jackfruit peels, custard apple peels andpomegranate peelswere further subjected to GC-MS analysis so as to investigate the type of compounds responsible for the observed promising and encouraging antimicrobial activity.

As seen from Table III, which gives the chemical composition of the major retention peaks obtained in GCMS analysis of acetoneextracts of the fruit peels, the acetone extract of pomegranate peel and jack fruit peel showed similar results depicting furanone (an aroma compound),furfural (heterocyclic aldehyde) and phenolic compounds (mainly benezenetriol) as the prominent retention peaks. It is clearly visible that the furanone peak retention area is maximum in custard apple peel extract $(82.82 \%)$ followed by the amounts observed in jackfruit peel $(59.47 \%)$ and pomegranate peel $(32.59 \%)$ extracts. On the other hand, the retention peak areas for furfural (along with imidazole) and phenolic compounds (mainly benezenetriol) are observed to be more in pomegranate peel extract compared to that got in jack fruit peel extract. In the GC-MS results of custard apple peel extract it is observed that there is only one major retention peak and it is that of furanone. The amount of phenolic compounds in the custard apple peel extract is found to be very negligible. Since the present study on antimicrobial activity results reveals potent antimicrobial potential of the acetone extracts of the fruit peels in the order pomegranate peels $>$ jackfruit peels $>$ custard apple peels, it can be speculated that furanone identified through GC-MS analysis in the extracts are one of the 
chemical class of compounds responsible for the observed antimicrobial activity, but since the amount of antimicrobial activity is seen to be more pronounced in the reverse order with respect to the content of furanone observed in the extracts, it could be reasonably argued that apart from furanone, the other prominent retention peaks of furfural(along with imidazole) and phenolic compounds (mainly benezenetriol) seems to have a vital role to play in the observed antimicrobial activity. This finding is supported by the fact that, pomegranate peel acetone extract which has shown the best antimicrobial activity in the present study has more content of furfural(along with imidazole) and phenolic compounds (mainly benezenetriol) as compared to the amount observed in jack fruit peel acetone extract which shows comparatively lesser antimicrobial activity.

GC-MS analysis of acetone extracts of pomegranate peels, jackfruit peels and custard apple peels reveal the chemical classes- furanone, furfural(along with imidazole) and phenolic compounds (mainly benezenetriol) to have a key role in the observed antimicrobial activity in these extracts. Furanone, which is present naturally in fruits as an aroma compound and as pheromones (Colin Slaughter 1999), has been reported as an antibacterial agent owing to its role in disrupting the quorum sensing property of bacteria (Wuetal. 2004; Morten Hentzeret al. 2002). The antibacterial potential of furanone has been studied and reported against nosocomial infections (Woo,Sang, Sung et al. 2007), against Staphylococcus epidermidis which is one of the most common bacterial isolates from medical devices infections due to biofilm formation (Baveja et al. 2004), and also seen to possess anti-inflammatory and analgesic property ( Alam et al. 2010). Though there are no direct reports of studies correlating furfural and antimicrobial activity, characterization of some antimicrobial substances from seed coat of Tamarindus indica Linn. has shown furfural as one of the compounds (Shital Waghmare et al. 2010). Furfural has many essential uses in the industry, apart from being used as one of the most widely used solvents, it is used in fungicides, germicides, herbicides and insecticides, and furfural also acts as an intermediate in the manufacture of many polymers (Abdul Azis Ariffin et al.2009). D. Wansaki et al (2011) have reported furfural production from peels of pineapple and papaya throughacid catalyzed hydrolysis. Thus the furfural analyzed in the pomegranate peel and jack fruit peel extracts in this study could serve as a source for furfural production. Imidazole peak which is seen only in the pomegranate peel extract, is an alkaloid and its role in the observed antimicrobial activity cannot be ruled out because imidazole is an important class of heterocycles and include many substances of both biological and chemical interest.There are reports of the role of imidazole in antifungal and antimycobacterial activity (Elena Banfi et al. 2006), in antibacterial activity (Khabnadidehet al. 2003; Rajiv Dahia 2008). Though the role of phenolic compounds in antimicrobial activity seen in pomegranate fruit peels has been reported in other reports. (Hany, Yehiaet al. 2011;Jahir,Alam,Khan and Sonali,Hanee 2011;Al Zorekyet al. 2009), no reports are cited linking acetone as a solvent for extracting out the antimicrobials, as is reported in our study.

Hence the present investigation results shows promising evidence of utilizing the crude acetone extracts of fruit peel wastes of pomegranate, jack fruit and custard apple assource for natural antimicrobials, as well as a source from which furfural could be derived.Although, further evaluation performed with the pure compounds is required for confirming the contribution of the identified biocompounds to the antimicrobial activity, this study definitely opens up the scope for further utilization of these waste products for therapeutic and industrial purpose.

\section{REFERENCES}

[1] Abdul AzisAriffin., Rosnah Mat Soom., Huey-Chern Boo., Chia-Chun Loi., Yuen-Hwa Chai., and AbdulKarim,S. M. 2009. Detection and determination of furfural in crude palm oil.Journal of Food, Agriculture and Environment.7: 136-138.

[2] Alam, M. M., Husain, A., Hasan, S. M., Khanna, S., and Shaquiquzzaman, M.2010.3-arylidene-5-(4isobutylphenyl)-2(3H)-furanones: a new series of anti-inflammatory and analgesic compounds having antimicrobial activity.J of Enzyme Inhib Med Chem. 25: 323-330.

[3] Al-Zoreky,N. S. 2009. Antimicrobial activity of pomegranate (Punicagranatum L.) fruit peels.International Journal of Food Microbiology. 134: 244-248.

[4] Ashok kumar,K., Narayani,M., Subanthini,A.,andJayakumar,M. 2011. Antimicrobial activity and phytochemical analysis of citrus fruit peels- Utilization of fruit wastes.International Journal of Engineering Science and Technology. 3: 54145420.

[5] Ayala Zavala,J.F., Vega Vega,V., Rosas Dominguez,C., PalafoxCarlos,H., Villa Rodriguez,J.A., Md. WasimSiddiqui, . Davila Aviria,J.E., and Gonzalez Aguilar,G.A. 2011. Agroindustrial potential of exotic fruit byproducts as a source of food additives.Food Research International. 44: 1866-1874.

[6] Bavejaa,J.K., Willcoxa, M.D.P., Humea,E.B.H., Kumarc,N., Odellb,R., and Poole-Warrenb, L.A. 2004. Furanones as potential anti-bacterial coatings on biomaterials.Biomaterials. 25: 5003-5012.

[7] Calzada, F., Yepez,Mulia, L., and Tapia, Contreras, A. 2007. Effect of Mexican medicinal plant used to treat trichomoniasis on Trichomonasvaginalis. J. Ethnopharmacol. 113: 248-251.

[8] Chandraju, S., Mythily, R., and Chidan Kumar, C. S. 2012. Qualitative chromatographic analysis of sugars present in non-edible rind portion of custard apple (AnnonaSquamosa. L).Journal of Chemical and Pharmaceutical Research. 4: 1312-1318.

[9] Chattopadhyay, D., Sinha, B., and Vaid, L.K. 1998. Antibacterial activity of Syzygiumspecies: a report. Fitopteria.69: 365-367. 
[10] Colin, Slaughter, J. 1999. The naturally occurring furanones: formation and function from pheromone to food. Biol Rev CambPhilos Soc. 7: 259-276.

[11] Elena,Banfi., Giuditta,Sciallino., Daniele,Zampieri., Maria,Grazia,Marmolo., Lucia,Vio., Marco,Ferrone., Maurizio,Fermeglia., Maria, Silvia,Paneni., and Sabrina,Pricl. 2006. Antifungal and antimycobacterial activity of new imidazole and triazole derivatives. A combined experimental and computational approach. J. Antimicrob. Chemother. 58: 76-84.

[12] Hany, M. Yehia., Manal, F. Elkhadragy., and Ahmed, E. Abdel Moneim. 2011. Antimicrobial activity of pomegranate rind peel extracts. African Journal of Microbiology Research. 4: 3664-3668.

[13] Jahir, Alam, Khan., and Sonali, Hanee. 2011. Antibacterial properties of Punica granatum peels. International Journal of Applied Biology and Pharmaceutical technology. 2: 23-27.

[14] Khabnadideha,S.,RezaeiaZ., Khalafi-Nezhadb,A., Bahrinajafia,R., Mohamadia,R., and Farrokhroza,A.A. 2003. Synthesis of N-Alkylated derivatives of imidazole as antibacterial agents. Bioorganic and Medicinal chemistry letters. 13: 2863-2865.

[15] Li, Yunfeng.,Guo, Changjiang., Yang, Jijun., Wei, Jingyu., Xu, Jing., and Cheng, Shuang. 2006. Evaluation of antioxidant properties of pomegranate peel extract in comparison with pomegranate pulp extract. Food Chemistry. 96: 254-260.

[16] Morten,Hentzer., Kathrin, Riedel., Thomas, B. Rasmussen., Arne,Heydorn., Jens, Bo, Andersen., Matthew, R. Parsek., Scott, A. Rice., Leo,Eberl., Søren,Molin.,Niels,Høiby., Staffan,Kjelleberg., and Michael,Givskov.2002. Inhibition of quorum sensing in Pseudomonas aeruginosa biofilm bacteria by a halogenated furanone compound. Microbiology. 148: 87-102.

[17] Narayani,T.G., and Gomathi,Priya, P. 2012. Biogas production through mixed fruit wastes biodegradation. $\mathrm{J}$ of scientific and industrial research.71: 217-220.

[18] Okeke, M. I., Iroegbu, C.U., Eze, E. N., Okoli, A.S., and Esimone, C.O. 2001. Evaluation of extracts of the root of Landolphia owerrience for antibacterial activity. J. Ethhnopharmacol.78 (2):19-127.

[19] Paterson,D.L., KoW.C., Von Gottberg,A., Mohapatra,S., Casellas,J.M., Goossens,H.,Mulazimoglu,L., $\quad$ Trenholme,G., Klugman,K.P., $\quad$ Bonomo,R.A., $\quad$ Rice,L.B., Wagener,M.M., McCormack,J.G. and Yu,V.L. 2004. International prospective study of Klebsiella pneumoniae bacteremia: implications of extendedspectrum beta-lactamase production in nosocomial Infections. Ann Intern Med.140: 26-32.

[20] Rajiv,Dahiya., 2008. Synthesis, Characterization and Antimicrobial Studies on Some Newer Imidazole Analogs. Sci Pharm.76: 217-239.

[21] Rao, A.V., and Rao, L.G. 2007. Carotenoids and Human health. Pharmacological Research.55: 207216.
[22] Shital, S. Waghmare., Dipali, Y. Jadhav., Jai, S. Ghosh., and Akshay, K. Sahoo. 2010. Characterization of some antimicrobial substances from seed coat of Tamarindus indica Linn. British Journal of Pharmacology and Toxicology 1: 29-32.

[23] Swaroopa, Rani,D., and Krishna, Nand. 2004. Ensilage of pineapple processing waste for methane generation. Waste Management. 24: 523-528.

[24] Theivasanthi, T., Venkadamanickam, G., Palanivelu, M., and Alagar, M. 2011.Nano sized Powder of Jackfruit Seed: Spectroscopic and Anti-microbial Investigative Approach. Nano Biomedicine and Engineering. 3 : 215-221.

[25] Vijayaraghavan,Krishna., Ahmad,Desa., and Ibrahim,Mohd,Khairil. 2006. Biohydrogen generation from jackfruit peel using anaerobic contact filter. International Journal of Hydrogen Energy. 31: 569579.

[26] Vikash,Kandari., and Sanjay, Gupta. 2012. Bioconversion of vegetable and fruit peel wastes in viable product. J. Microbiol. Biotech. Res.2: 308-312.

[27] Wankasi,D., Tarawou,T. J., and Yabefa,J. A. 2011. Furfural production from the peels of ripe pawpaw (Carica papayal.) and pineapple (Ananas comosus) fruits by acid catalyzed hydrolysis. Am. J. Food. Nutr. 1: 136-140.

[28] Woo, Sang,Sunga., Hyun, Jun,Junga., Keunnam, Parka., Hyun,Soo,Kimb., In-Seon,Leeb., and Dong, Gun,Leea. 2007. 2， 5-dimethyl-4-hydroxy-3(2H)furanone (DMHF); antimicrobial compound with cell cycle arrest in nosocomial pathogens.Life Sciences. 80: $586-591$.

[29] Wu, H., Song,Z., Hentzer,M., Andersen,J. B., Molin,S., Givskov,M.,andHøiby,N. 2004. Synthetic furanones inhibit quorum-sensing and enhance bacterial clearance in Pseudomonas aeruginosa lung infection in mice.J. Antimicrob. Chemother.53: 1054-1061. 
Table 1: Antimicrobial activity of fruit peel extracts against pathogenic bacteria.

\begin{tabular}{|c|c|c|c|c|c|c|c|c|c|}
\hline \multirow{2}{*}{\multicolumn{2}{|c|}{$\begin{array}{l}\text { Microorganisms } \\
\text { Fruit peel solvent* }\end{array}$}} & E. coli & $\begin{array}{l}\text { K.pneum } \\
\text { oniae }\end{array}$ & $\begin{array}{l}\text { P.aerugi } \\
\text { nosa }\end{array}$ & $\begin{array}{l}\text { P.vulgar } \\
\text { is }\end{array}$ & S.typhii & $\begin{array}{l}\text { S.pyroge } \\
\text { nes }\end{array}$ & S.aureus & $\begin{array}{l}\text { E.faecali } \\
s\end{array}$ \\
\hline & & \multicolumn{8}{|c|}{ Inhibition zone diameter $(\mathrm{mm})^{\dagger, t}$} \\
\hline $\begin{array}{l}\text { Pineapplepeel } \\
\text { extract } \\
(5 \mathrm{mg} / 100 \\
\mu \mathrm{l})\end{array}$ & CPAB & $\begin{array}{l}12 \pm 0.5 \\
- \\
12 \pm 0.5 \\
-\end{array}$ & $\begin{array}{l}- \\
- \\
12 \pm 0.4 \\
12 \pm 0.5\end{array}$ & $\begin{array}{l}12 \pm 0.4 \\
- \\
15 \pm 0.5 \\
-\end{array}$ & $\begin{array}{l}12 \pm 0.5 \\
- \\
13 \pm 0.5 \\
12 \pm 0.3\end{array}$ & $\begin{array}{l}12 \pm 0.5 \\
- \\
18 \pm 0.4 \\
-\end{array}$ & $\begin{array}{l}12 \pm 0.4 \\
14 \pm 0.5 \\
14 \pm 0.5 \\
12 \pm 0.3\end{array}$ & $\begin{array}{l}- \\
- \\
12 \pm 0.5 \\
-\end{array}$ & $\begin{array}{l}14 \pm 0.5 \\
- \\
12 \pm 0.3 \\
-\end{array}$ \\
\hline $\begin{array}{l}\text { Custard apple } \\
\text { peel extract } \\
(5 \mathrm{mg} / 100 \\
\mu \mathrm{l})\end{array}$ & $\begin{array}{l}\mathrm{C} \\
\mathrm{P} \\
\mathrm{A} \\
\mathrm{B}\end{array}$ & $\begin{array}{l}12 \pm 0.5 \\
- \\
20 \pm 0.4 \\
-\end{array}$ & $\begin{array}{l}15 \pm 0.5 \\
- \\
15 \pm 0.4 \\
15 \pm 0.5\end{array}$ & $\begin{array}{l}17 \pm 0.3 \\
- \\
18 \pm 0.4 \\
18 \pm 0.5\end{array}$ & $\begin{array}{l}15 \pm 0.5 \\
11 \pm 0.4 \\
20 \pm 0.5 \\
16 \pm 0.5\end{array}$ & $\begin{array}{l}13 \pm 0.5 \\
- \\
20 \pm 0.5 \\
11 \pm 0.5\end{array}$ & $\begin{array}{l}14 \pm 0.5 \\
- \\
20 \pm 0.5 \\
15 \pm 0.4\end{array}$ & $\begin{array}{l}13 \pm 0.4 \\
- \\
20 \pm 0.4 \\
15 \pm 0.5\end{array}$ & $\begin{array}{l}13 \pm 0.5 \\
14 \pm 0.5 \\
20 \pm 0.4 \\
16 \pm 0.4\end{array}$ \\
\hline $\begin{array}{l}\text { Jack fruit } \\
\text { peel extract } \\
(5 \mathrm{mg} / 100 \\
\mu \mathrm{l})\end{array}$ & $\begin{array}{l}\mathrm{C} \\
\mathrm{P} \\
\mathrm{A} \\
\mathrm{B}\end{array}$ & $\begin{array}{l}12 \pm 0.5 \\
15 \pm 0.5 \\
20 \pm 0.3 \\
-\end{array}$ & $\begin{array}{l}17 \pm 0.5 \\
- \\
30 \pm 0.5 \\
12 \pm 0.3\end{array}$ & $\begin{array}{l}20 \pm 0.5 \\
- \\
25 \pm 0.4 \\
12 \pm 0.5\end{array}$ & $\begin{array}{l}17 \pm 0.4 \\
- \\
20 \pm 0.4 \\
12 \pm 0.5\end{array}$ & $\begin{array}{l}15 \pm 0.5 \\
- \\
24 \pm 0.4 \\
13 \pm 0.5\end{array}$ & $\begin{array}{l}12 \pm 0.5 \\
12 \pm 0.5 \\
25 \pm 0.5 \\
12 \pm 0.5\end{array}$ & $\begin{array}{l}15 \pm 0.5 \\
12 \pm 0.5 \\
24 \pm 0.4 \\
12 \pm 0.5\end{array}$ & $\begin{array}{l}17 \pm 0.5 \\
15 \pm 0.5 \\
30 \quad \pm \\
0.54 \\
12 \pm 0.5\end{array}$ \\
\hline $\begin{array}{l}\text { Pomegranate } \\
\text { peel extract } \\
(5 \mathrm{mg} / 100 \\
\mu \mathrm{l})\end{array}$ & $\begin{array}{l}\mathrm{C} \\
\mathrm{P} \\
\mathrm{A} \\
\mathrm{B}\end{array}$ & $\begin{array}{l}- \\
- \\
33 \pm 0.4 \\
12 \pm 0.5\end{array}$ & $\begin{array}{l}14 \pm 0.4 \\
- \\
30 \pm 0.3 \\
14 \pm 0.5\end{array}$ & $\begin{array}{l}15 \pm 0.5 \\
- \\
32 \pm 0.4 \\
13 \pm 0.5\end{array}$ & $\begin{array}{l}14 \pm 0.5 \\
- \\
30 \pm 0.5 \\
20 \pm 0.3\end{array}$ & $\begin{array}{l}15 \pm 0.5 \\
- \\
31 \pm 0.4 \\
22 \pm 0.5\end{array}$ & $\begin{array}{l}- \\
- \\
30 \pm 0.4 \\
16 \pm 0.3\end{array}$ & $\begin{array}{l}12 \pm 0.5 \\
- \\
35 \pm 0.5 \\
-\end{array}$ & $\begin{array}{l}- \\
- \\
35 \pm 0.5 \\
15 \pm 0.4\end{array}$ \\
\hline $\begin{array}{l}\text { Papaya } \\
\text { peel extract } \\
(5 \mathrm{mg} / 100 \\
\mu \mathrm{l})\end{array}$ & $\begin{array}{l}\mathrm{C} \\
\mathrm{P} \\
\mathrm{A} \\
\mathrm{B}\end{array}$ & $\begin{array}{l}15 \pm 0.4 \\
- \\
12 \pm 0.3 \\
-\end{array}$ & $\begin{array}{l}14 \pm 0.5 \\
- \\
- \\
-\end{array}$ & $\begin{array}{l}13 \pm 0.5 \\
- \\
12 \pm 0.3 \\
11 \pm 0.5\end{array}$ & $\begin{array}{l}14 \pm 0.5 \\
- \\
- \\
12 \pm 0.5\end{array}$ & $\begin{array}{l}14 \pm 0.5 \\
- \\
- \\
-\end{array}$ & $\begin{array}{l}12 \pm 0.5 \\
- \\
- \\
-\end{array}$ & $\begin{array}{l}13 \pm 0.3 \\
- \\
12 \pm 0.4 \\
-\end{array}$ & $\begin{array}{l}13 \quad \pm \\
0.4 \ddagger \\
- \\
-\end{array}$ \\
\hline $\begin{array}{l}\text { Standard } \\
\text { antibiotic } \\
\text { amikacin } \\
(50 \mu \mathrm{g} / 100 \\
\mu \mathrm{l})\end{array}$ & & $24 \pm 0.3$ & $22 \pm 0.4$ & $20 \pm 0.5$ & $23 \pm 0.3$ & $20 \pm 0.5$ & $20 \pm 0.3$ & $25 \pm 0.5$ & $28 \pm 0.4$ \\
\hline
\end{tabular}


Table 2: $\mathrm{MIC}$ and MBC of acetone extracts of fruit peels

\begin{tabular}{|l|l|l|l|l|l|l|}
\hline \multirow{2}{*}{ Microorganism } & \multicolumn{2}{|l|}{$\begin{array}{l}\text { Acetone extract of } \\
\text { custard apple peel }\end{array}$} & $\begin{array}{l}\text { Acetone extract of } \\
\text { jack fruit peel }\end{array}$ & \multicolumn{2}{l}{$\begin{array}{l}\text { Acetone extract of } \\
\text { pomegranate peel }\end{array}$} \\
\cline { 2 - 7 } & $\begin{array}{l}\text { MIC } \\
(\mathrm{mg} / \mathrm{ml})\end{array}$ & $\begin{array}{l}\text { MBC } \\
(\mathrm{mg} / \mathrm{ml})\end{array}$ & $\begin{array}{l}\text { MIC } \\
(\mathrm{mg} / \mathrm{ml})\end{array}$ & $\begin{array}{l}\text { MBC } \\
(\mathrm{mg} / \mathrm{ml})\end{array}$ & $\begin{array}{l}\text { MIC } \\
(\mathrm{mg} / \mathrm{ml})\end{array}$ & $\begin{array}{l}\text { MBC } \\
(\mathrm{mg} / \mathrm{ml})\end{array}$ \\
\hline Escherichia coli & 1.75 & 2.5 & 1.75 & 2.5 & 0.875 & 1.75 \\
\hline Klebsiella pneumoniae & 2.5 & 5.0 & 1.75 & 5.0 & 1.75 & 2.5 \\
\hline Pseudomonas aeruginosa & 2.5 & 5.0 & 1.75 & 5.0 & 1.75 & 2.5 \\
\hline Proteus vulgaris & 1.75 & 2.5 & 1.75 & 2.5 & 0.875 & 1.75 \\
\hline Salmonella typhii & 1.75 & 2.5 & 1.75 & 2.5 & 0.875 & 1.75 \\
\hline Streptococcus pyrogenes & 1.75 & 2.5 & 1.75 & 2.5 & 0.875 & 1.75 \\
\hline Staphylococcus aureus & 1.75 & 2.5 & 1.75 & 2.5 & 0.875 & 1.75 \\
\hline Enterococcus faecalis. & 0.875 & 2.5 & 0.875 & 2.5 & 0.875 & 2.5 \\
\hline
\end{tabular}

Table 3: Chemical composition of the major retention peaks obtained in GC-MS analysis of the acetone extracts of fruit peels showing high antimicrobial activity.

\begin{tabular}{|l|l|l|l|l|}
\hline Name of compound & $\begin{array}{l}\text { Retention } \\
\text { time (min) }\end{array}$ & $\begin{array}{l}\text { \% in acetone extract of } \\
\text { pomegranate peel }\end{array}$ & $\begin{array}{l}\text { \% in acetone extract of } \\
\text { jackfruit peel }\end{array}$ & $\begin{array}{l}\text { \% in acetone extract of } \\
\text { custard apple peel }\end{array}$ \\
\hline Furanone & 5.10 & 32.59 & 59.47 & 82.82 \\
\hline & 5.13 & & & \\
\hline & 7.21 & 0.64 & & \\
\hline & 5.36 & 9.15 (including Imidazole) & & \\
\hline & 5.37 & & 4.64 & \\
\hline & 14.21 & & 9.26 & \\
\hline Furfural & 14.22 & 12.73 & & \\
\hline 1,4 benezenediol & 10.48 & 0.49 & & \\
\hline Phenol & 14.72 & & & \\
\hline & 15.57 & 0.46 & 0.34 & \\
\hline & 23.45 & & & \\
\hline & 53.93 & 0.67 & & \\
\hline & & & & \\
\hline & 17.10 & 14.06 & 3.19 & \\
\hline & 17.12 & & & \\
\hline & 17.63 & & & \\
\hline & 18.77 & 0.54 & & \\
\hline
\end{tabular}

a Compounds listed in order of their elution from column. 